\title{
Evaluation Study of Software Quality Management (SQM) and Quantitative Process Management (QPM) in Pakistan Software Houses
}

\author{
Muhammad Haroon \\ Department of Computer Science \& Information Technology University of Gujrat Lahore Sub Campus, Lahore, \\ Pakistan. \\ E-mail: haroon@uoglahore.edu.pk haroon.capricorn@gmail.com
}

Received:08 March 2020; Accepted: 03 May 2020; Published: 08 August 2020

\begin{abstract}
Key Process Areas (KPAs) for Software Engineering Institute (SEI) Maturity Level 4 can be described in terms of Quantitative Process Management (QPM) which is the metric to control the quantitative performance of a software project. On the other hand, Software Quality Management (SQM) monitors and controls the quality of the project. The survey conducted in this paper covers around 20 software houses of Pakistan. The study revealed that there is weakness in both KPAs, SQM and QPM. Each KPA defines a set of rules that are necessary to be followed to meet the standard but many organizations fail to follow these rules defined in every KPA. If specified and appropriate measures are taken, the software industry will lift it up to the higher CMMI Level.
\end{abstract}

Index Terms: Key Process Areas, KPA, Capability Maturity Mode, CMMI, Software Quality Management, SQM, Quantitative Process Management, QPM, Software House, Pakistan Software House.

\section{Introduction}

World is moving towards automation testing in 21st century due to its surprising benefits and advancements in the field of software quality assurance. Pakistan is one of the growing country in Information Technology Sector. As Software Houses from small to large scale in Pakistan earns millions of rupees per annum [1], its software industry plays a strategic role in other parts of the region. Information Technology industry in Pakistan has always been an important factor towards Economy.

As with the growing field, CMMI practices and Key Process Areas (KPAs) must be followed to smooth the working and to remain in the ranking of world best software industries. In the past, it was assumed by software community that CMMI practices or Key Process Areas (KPAs) are only for military organizations due to the sensitivity of data and program [2] but now it has become the need of every scale software industry. Basically CMMI has five levels of maturity, Initial, Managed, Defined, Quantitatively Managed and Defined. Key Process Areas (KPAs) for Software Engineering Institute (SEI) Maturity Level 4 (Quantitatively Managed) can be described in terms of Quantitative Process Management (QPM) and the Software Quality Management (SQM). A glimpse of Pakistan's top CMMI Level software industries have been listed in table 1.

Table 1. CMMI Levels of Pakistan Software Industries

\begin{tabular}{cc}
\hline Company Name & CMMI Level \\
\hline NCR Corporation & 5 \\
Netsol Limited & 4 \\
Kalsoft & 3 \\
Systems Limited & 3 \\
DPS & 2
\end{tabular}

It has been observed that majority of the software companies in Pakistan do not follow the rules defined by KPAs which keep those companies away from achieving a good CMMI Level. The purpose of the research conducted here is to highlight the key areas where problem exists.

In this paper, result of a survey is discussed which is conducted in software houses of Pakistan regarding key process areas and assessment results are generated that where is the weakness or problem in some area. Based upon the research study, some solution measures are proposed to better the quality of developed products and to take software house 
at higher level of CMMI.

\section{Importance of Software Test Automation in Improving KPAs}

Defect detection before delivery of the system is one of the critical phase of SDLC. If defect remains undetected in the production environment, the results could be devastated may result in client dissatisfaction and market devaluation [4]. It lowers the value of a software house which has direct affect on that software house's CMMI scale.

According to an estimate, it can be said that testing phase takes over half of the project budget [3]. Poor or no testing of a system increases project overall cost. Software industries in United States lose 21.2 billion dollars annually due to poor manual testing which skips many minor and major test cases in the system developed [3]. As described earlier, finding of a smallest test case is NP-Complete problem, so it is very difficult for SQA engineer to find all test cases for a system or a module of a system. GUI object size and color testing is also not easy with manual testing.

\section{Software Quality Management (SQM)}

Software Quality Management (SQM) refers to the process of checking and maintaining the quality of project being developed to achieve specific and defined goals [5]. These goals are defined to develop a software product in software house and mandatory to fulfill to have good reputation. Several strategies need to be established to smoothen the software process [6]. To move towards high CMMI levels, an organization must have organized and managed organizational processes, software development standards and best industry practices [7].

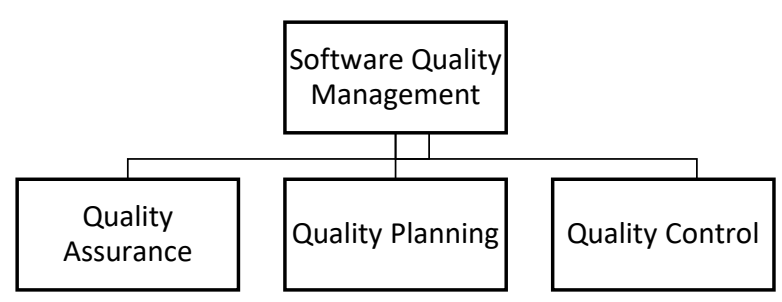

Fig.1. Components of Software Quality Management (SQM)

The activities in SQM covers three activities, Quality Assurance, Planning and Quality Control [8]. The quality management is somehow different from the other fields like in manufacturing or engineering field needs to follow the predefined requirements and specifications for a particular product but the software industry has a light flexibility in this regard which is based on the a particular customer's requirements and the standards of that organization [9]. Any software product meets with customer requirement is said to be the perfect one.

According to a study in [10], a series of steps are defined to manage software quality. The detail is in following:

Policies and plans of quality must be defined first to proceed further.

A training for Development and Quality Assurance team is required for better understanding of the system.

Establishment of quality process management is necessary.

A process for statistical control of software must be defined.

Overview of all software artifacts before development is required.

Proper listing of all errors and bugs found in the system and adding them in a repository to avoid mistakes in future.

A continuous process of improving all mentioned steps.

Some other factors must also be considered to manage the quality which includes the budget allocation, schedules of deadline, inadequate software tools, weak or no training of staff, lack of awareness about the process and insufficient management support.

\section{Quantitative Process Management(QPM)}

This type of process has the purpose to control the process management of software project quality in quantitative manner [5]. This actually aims to measure project requirements with the product delivered or developed. It is a trade-off between quality of software product and the delivery deadline. If a software house focuses so much on maintaining the quality and take advance measures to ensure the quality then it'd be difficult for it to deliver product on or before deadline or quality may be suffer in delivering product on deadline but this factor can be controlled. The SEIs recommendations on CMMI Level 4 needs that a software house must be able to quantitatively manage, understand and control its processes 
[11][14].

It includes some areas like:

Identification of sub-processes based on historical stability and data capability.

Maintaining the understanding of variation using analytical techniques.

Creating repository of quality management and statistical data in an organization.

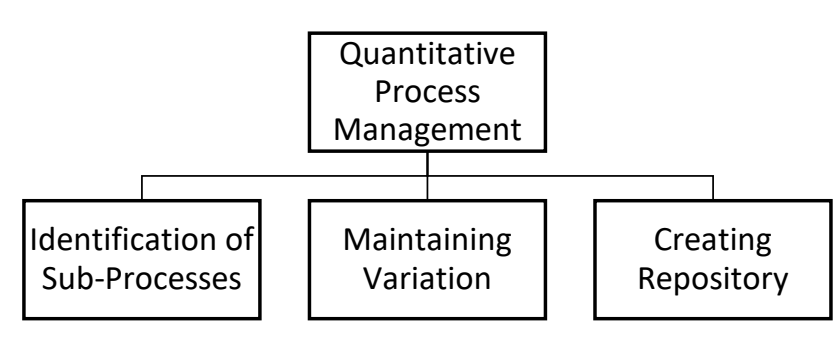

Fig.2. Components of Quantitative Process Management (QPM)

\section{Difference between SQM and QPM}

There is a very narrow line that separates SQM from QPM in terms of their concept [15]. Both are the management processes. SQM aims to manage the quality of software as per the requirements and the needs of customer whereas the QPM is a measure to manage the product deliverables quantitatively to meet process performance objectives [13].

\section{Survey}

A survey is conducted to evaluate Software Quality Management (SQM) and Quantitative Process Management (QPM) is conducted in Pakistan's Software Houses. This survey covered 20 software houses of Pakistan.

\subsection{Survey Methodology}

This survey is based on questionnaire forms. A questionnaire having few questions with possible options is prepared and being filled using Google Forms from higher management of software house. Then the results are retrieved, analyzed and discussed.

\subsection{Survey Audience}

This survey questionnaires filled by higher authorities of Software Houses of Pakistan. Twenty software houses are selected to conduct this survey. Besides this, observation of activities and environment was performed in parallel to the written survey in the actual software development process. Data about the software companies and their nature were gathered through print and electronic media.

\subsection{Questions Included}

Questions related to Key Practices of the Quality Management (SQM) and Quantitative Process Management (QPM) are added in the questionnaire form. Format of each question is like a question with five possible options (Always=5, Often $=4$, Sometimes $=3$, Rarely $=2$, Never $=1$ ).

These questions are listed as:

1. Sufficient and Adequate resources and software tools provided for quantitative process management activities (E.g. finance of project management tools and organizational measurement program) by the Software House.

2. Software Project in organization follows a documented plan for conducting quantitative process management?

3. The process capability of the software company's standard software process termed in quantitative terms?

4. Measurements used to establish the status of activities for managing software quality.

5. Software project follows a pre-defined written policy for measuring and controlling the performance of the software project's defined software process.

6. Activities for quantitative process management passed with the project manager on both a periodic and eventdriven basis?

7. Activities for managing software quality planned for the project?

8. Software project uses measurable objectives for managing the quality the software product.

9. Team members in the software house receive required training in software quality management. Annually

Activities done for software quality management approved by senior management on a periodic basis (E.g. Monthly, 


\subsection{Results}

Above mentioned questionnaire is being filled by 20 software houses and the calculated results are maintained in following table.

Table 2. Survey Results

\begin{tabular}{cccccc}
\hline Q\# & Always & Often & Sometimes & Rarely & Never \\
\hline 1 & 6 & 8 & 4 & 1 & 1 \\
2 & 2 & 2 & 8 & 5 & 3 \\
3 & 5 & 4 & 6 & 2 & 3 \\
4 & 4 & 4 & 4 & 2 & 6 \\
5 & 10 & 5 & 3 & 1 & 1 \\
6 & 8 & 6 & 3 & 2 & 1 \\
7 & 8 & 8 & 2 & 1 & 1 \\
8 & 6 & 7 & 4 & 1 & 2 \\
9 & 7 & 4 & 5 & 1 & 3 \\
10 & 11 & 5 & 1 & 2 & 1 \\
& $\mathbf{3 3 . 5 \%}$ & $\mathbf{2 6 . 5 \%}$ & $\mathbf{2 0 \%}$ & $\mathbf{9 \%}$ & $\mathbf{1 1 \%}$ \\
\hline
\end{tabular}

The above table shows the complete statistics received from survey.

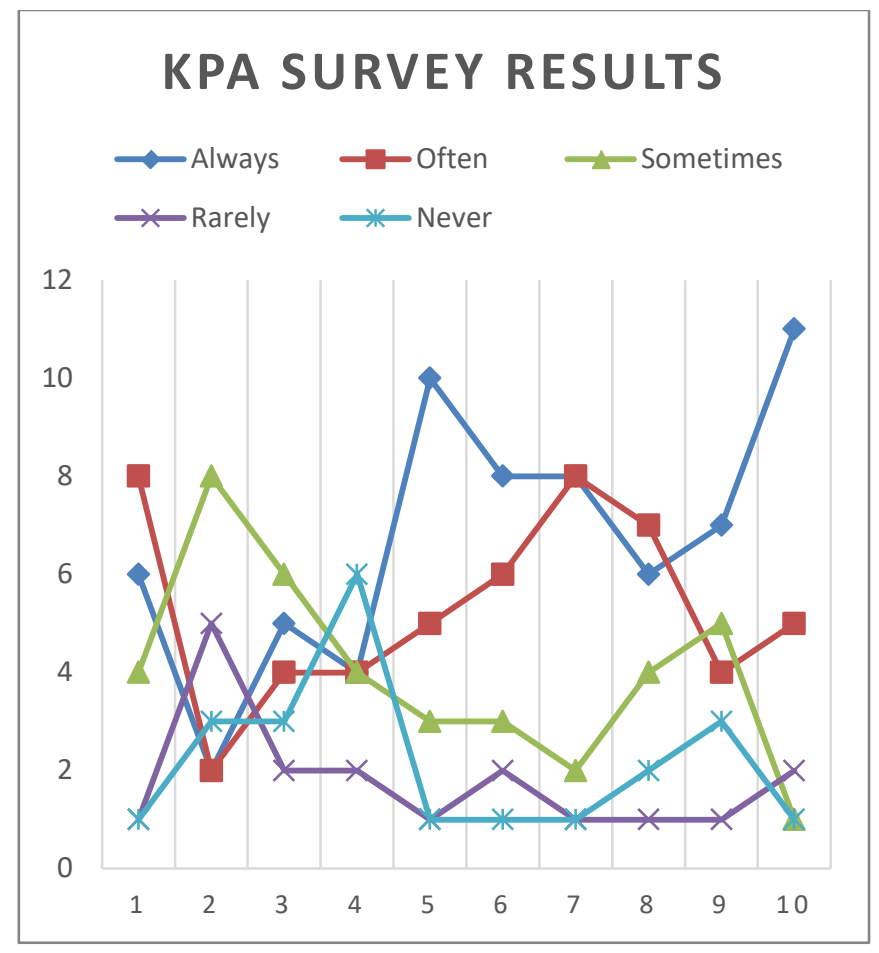

Fig.3. KPA Survey Results 


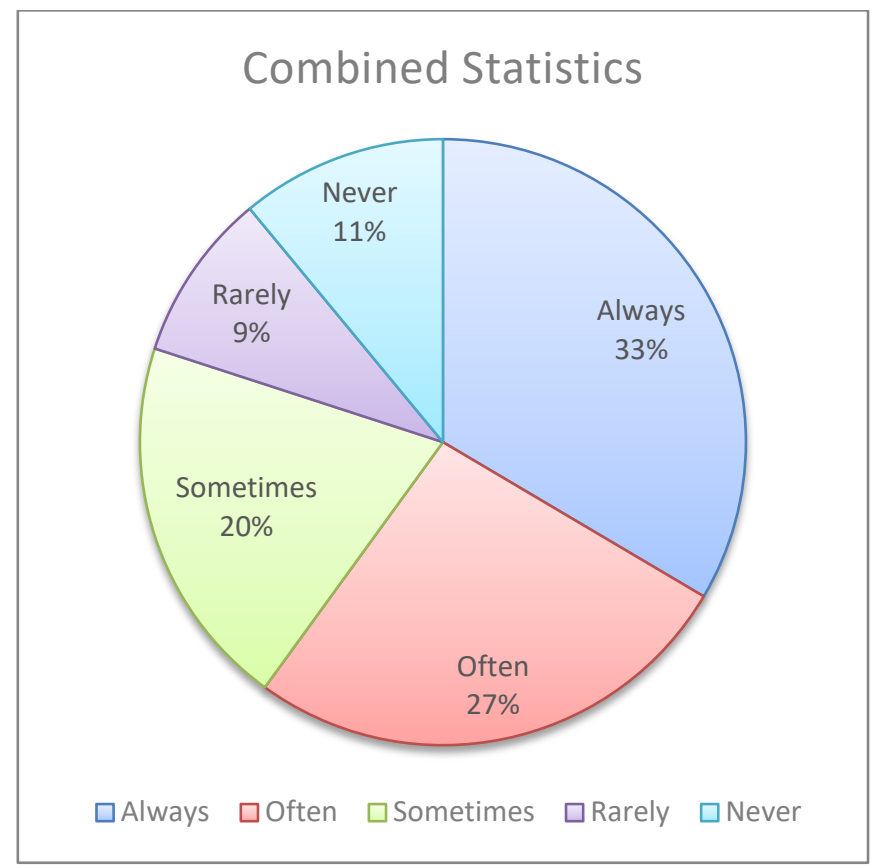

Fig.4. Combined Statistics of Result

\subsection{Discussion Based On Results}

There were 10 questions included in the survey which is filled by management or owners of software companies in Pakistan. All the questions were related to SQM and QPM. We can see in combined statistics (Fig.4) that 33\% (highest) software houses “Always” use the features of SQM and QPM and tried to make their position good in CMMI Level race. $27 \%$ often use these practices and only $11 \%$ never use the practices of SQM and QPM.

Here, we'll discuss the detailed question wise results.

Q\#1: Sufficient and Adequate resources and software tools provided for quantitative process management activities (E.g. finance of project management tools and organizational measurement program) by the Software House.

Discussion: 6 and 8 software houses out of 20 marked that they provide Sufficient and Adequate resources to its staff as "Always" and "Often" respectively which is quite a good sign because 14 out of 20 (70\%) companies are capable enough to provide resources which is the basic need of staff. This is in accordance with the standards set by SEI.

Q\#2: Software Project in organization follows a documented plan for conducting quantitative process management?

Discussion: Based upon the results received, we can see lack here that only 2+2 out of 20 software houses agreed to follow documentation, 8 software houses follow "sometimes" and 5+3 follows rarely or never used. This area is alarming as we can see that Pakistan software houses rarely follows documentation to develop a software product and this is one of the important matric of SEI.

Q\#3: The process capability of the software company's standard software process termed in quantitative terms?

Discussion: We got mixed results here as 5 companies agreed to this, 4 marked often.

Q\#4: Measurements used to establish the status of activities for managing software quality.

Discussion: There is no prominent behavior found here as $4+4$ software houses said that they establish the status of activities. And 2+6 rarely or never do this and rest do sometimes.

Q\#5: Software project follows a pre-defined written policy for measuring and controlling the performance of the software project's defined software process.

Discussion: Here, we found a positive sign because there is a clean curve of answers behavior here. 15 out of 20 (75\%) software companies follow pre-defined written policy for measuring and controlling the performance of the software. This must also be followed in rest of the companies.

Q\#6: Activities for quantitative process management passed with the project manager on both a periodic and eventdriven basis?

Discussion: A good trend also presented here. A good amount of software houses admitted that activities for quantitative process management are passed with the project manager on both a periodic and event-driven basis. Sometimes, depends upon requirements, report is approved by project manager on a defined period of time or event based. A very few population does not follow this practice.

Q\#7: Activities for managing software quality planned for the project?

Discussion: This is also a good sign from the side of software houses that $8+8$ (80\%) software houses has the planned activities and very negligible amount of percentage don't follow this.

Q\#8: Software project uses measurable objectives for managing the quality the software product. 
Discussion: A good amount of software houses use measurable objectives for managing the quality the software product

Q\#9: Team members in the software house receive required training in software quality management.

Discussion: Training of staff is one of the important factor because without training, the performance is affected. Around half, 11 out of 20 software houses arranges training for its staff and 3 software houses (15\%) never conducts training which is not a good sign.

Q\#10: Activities done for software quality management approved by senior management on a periodic basis (E.g. Monthly, Annually etc.)?

Discussion: This is also a good sign from the side of software houses that $11+5(80 \%)$ software houses has the approved activities and very negligible amount of percentage don't follow this.

\section{Conclusion}

This paper was purely based on the survey which is conducted successfully in twenty software houses of Pakistan to know the fulfillment and practices of two key process areas, Software Quality Management (SQM) and Quantitative Process Management (QPM). The results are compiled, analyzed and discussed which is the representation of the stand of Pakistan's software industry and it also helps us to give the direction towards getting a good CMMI Level. We have (concluded based upon survey results) that some software companies are doing good in these areas as the results are satisfactory for some but majority of software companies lack in fulfilling few areas which is the weakness of the system. The weak areas push those companies away from achieving a good CMMI level. The root of this survey was to know the weak areas so that some advance measures could be suggested which will help these companies to achieve a good level of CMMI. These all areas can be properly managed to move towards high CMMI Level.

\section{References}

[1] Heeks, R.B. (2002) i-Development not e-development, Journal of International Development, 14(1): 1-12.

[2] Current Trends In The Adoption Of The CMMI Product Suit, Dave Zubrow, 27th Annual international computer software and application conference 2003.

[3] Kit, E., Software Testing in the Real World: Improving the Process. Addison-Wesley, Reading, MA, USA, 1995.

[4] Tassey, G., The Economic Impacts of Inadequate Infrastructure for Software Testing. U.S. National Institute of Standards and Technology report, RTI Project Number 7007.011, 2002.

[5] Paulk M. C., Weber C. V., Garcia S. M., Chrissis M. B., and Bush M. (1993). Key Practices of the Capability Maturity Model, Version 1.1. Technical Report CMU/SEI-93-TR-025 ESC-TR-93-178, Software Engineering Institute, Carnegie Mellon University, Pittsburgh, Pennsylvania.

[6] Paulk M. C., Weber C. V., Curtis B., \& Chrissis M. B. (1995). The Capability Maturity Model: Guidelines for Improving the Software Process. Addison - Wesley, Boston

[7] Sommerville, I. (2011). "Chapter 24: Quality Management". Software Engineering (9th ed.). Addison-Wesley. pp. 651-680. ISBN 9780137035151.

[8] Zsolt, U. (February 2014). "Software quality management". Software Development Processes and Software Quality Assurance. University of Pannonia. pp. 117-121. Retrieved 7 December 2017.

[9] Sommerville I. (2006). Quality Management. Software Engineering, 8th edition. Chapter 27 Slides. AddisonWesley, England.

[10] Humphrey W. S. (2008). The Software Quality Challenge. CROSSTALK: The Journal of Defense Software Engineering. pp 4 9.

[11] Sowunmi O. Y., Misra S., Fernandez-Sanz L. , Crawford B. and Soto R. (2016). An empirical evaluation of software quality assurance practices and challenges in a developing country: a comparison of Nigeria and Turkey.SpringerPlus20165:1921. DOI: 10.1186/s40064-016-3575-5.

[12] Malik Hneif, Siew Hock Ow, “Review of Agile Methodology in Software Development”, IJRR in Applied Sciences, Vol 1 Issue 1 , Oct 2009.

[13] Moses Kehinde Aregbesola, "Evaluation of Quantitative Process and Software Quality Management in the Nigerian SoftwareHouse”, International Journal of Computer Applications, Volume 168 No.1, June 2017. [14] Aregbesola M. K. and Oluwade B. A. (2014). An Experimental Evaluation of Defect Prevention and Change Management in Software Process Optimization in the Nigerian Software Industry. ARPN Journal of Systems and Software Vol.4, No.1, pp. 5-11.

[14] Hikichi K., Yonemitsu T., Fukuchi Y., Fushida K. and Iida H.(2005). An assistance method of incorporating quantitative management indicator into software development process. Hitachi, Ltd., Shinagawa, Tokyo, Japan. 


\section{Authors' Profile}

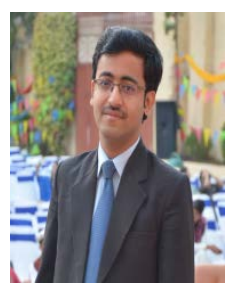

Muhammad Haroon is working as Lecturer and Project Manager Officer for Undergraduate Final Year Projects at University of Gujrat Lahore Sub Campus Lahore Pakistan and graduate of MS Computer Science with the specialization of Database and Data Mining at Virtual University of Pakistan. His areas of interest are Data Science, Machine Learning, Data Mining and Data Process.

How to cite this paper: Muhammad Haroon, " Evaluation Study of Software Quality Management (SQM) and Quantitative Process Management (QPM) in Pakistan Software Houses ", International Journal of Education and Management Engineering (IJEME), Vol.10, No.4, pp.40-46, 2020. DOI: 10.5815/ijeme.2020.04.05 